\title{
The value of colonoscopy to assess rectal bleeding in patients referred from Primary Care Units
}

\author{
A. Sánchez, C. Muñoz, L. Bujanda ${ }^{1}$, C. Iriondo, A. Gil-Molet, A. Cosme ${ }^{1}$, C. Sarasqueta ${ }^{1}$ and \\ M. Echenique-Elizondo ${ }^{2}$
}

Department of Gastroenterology. Hospital San Eloy. Baracaldo. ${ }^{1}$ Hospital Donostia. San Sebastián. ${ }^{2}$ School of Medicine. Basque Country University. San Sebastián. Guipúzcoa, Spain

\begin{abstract}
Objectives: rectal bleeding is very common in the general population. It is produced mainly because of benign disease originating in the anus and the rectum. Our aim was to evaluate the need for colonoscopy in patients presenting with rectal bleeding.

Patients and methods: patients referred from Primary Care Units and complaining of rectal bleeding were included prospectively in a three-month study. All patients underwent a careful medical history along with physical examination, laboratory tests, and colonoscopy.

Results: 126 patients with a mean age of 49.2 years (range: 19-80) were studied. Rectal digital examination was abnormal in 75 cases (59.5\%). Severe disease was encountered in 22 patients (neoplasm, angiodysplasia, and inflammatory bowel disease); 10 patients had polyps, 6 had colorectal cancer, and 6 had inflammatory bowel disease. Out of 63 patients younger than 50 years, 5 had severe disease, all of them in the form of inflammatory bowel disease.

Conclusions: a neoplasm of the rectum and colon in patients younger than 50 years is a rare event. A colonoscopy must be performed in this group of patients to rule out inflammatory bowel disease.
\end{abstract}

Key words: Rectal bleeding. Age. Colonoscopy. Primary Care Units.

Sánchez A, Muñoz C, Bujanda L, Iriondo C, Gil-Molet A, Cosme A, Sarasqueta C, Echenique-Elizondo M. The value of colonoscopy to assess rectal bleeding in patients referred from primary care units. Rev Esp Enferm Dig 2005; 97: 870-876.

Recibido: 15-04-05.

Aceptado: 28-06-05.

Correspondencia: Miguel Echenique Elizondo. Facultad de Medicina. UD San Sebastián. Paseo Dr. Beguiristáin, 105. 20014 San Sebastián. Guipúzcoa.e-mail: gepecelm@sc.ehu.es

\section{BACKGROUND}

Rectal bleeding is a common consultation reason in Primary Care as well as in Gastroenterology clinics. In a review carried out in 1992 the incidence of rectal bleeding in the general population medical records was $20 \%$ in the year before consultation, $7-16 \%$ in the previous six months and $2 \%$ (1-3) in the last two weeks. However, the true incidence can be higher than these figures because patients do not check usually their stool in toilets (4). Despite this high incidence, different studies estimate that only 13 to $45 \%$ of patients complaining from rectal bleeding consult, with the younger population being more concerned than the older one $(5,6)$. It has been estimated that 4-6 cases of rectal bleeding per 1,000 medical visits are seen by family doctors, and 0.8 are referred to the specialist (1). In our own experience with unpublished data in a specialized clinic we found that out of 309 patients referred for the first time, 29 had rectal bleeding $(9 \%)$.

In patients older than 50, endoscopy (sigmoidoscopycolonoscopy) is advised because of a higher risk of severe disease, mainly colorectal cancer (CRC).

In subjects younger than 40 and presenting with rectal bleeding without other risk factors and benign disease on clinical examination, the latest recommendations including one from the Spanish Association of Gastroenterology do not advise routine endoscopic examination (7). Anuscopy is advised only in the case of non-evident anal disease. In this group of patients the majority presents with benign anorectal disease (fissuration or hemorrhoids) and very exceptionally with IBD or neoplasms.

Our aim is to evaluate the cause of rectal bleeding on patients referred from Primary Care Units and the true value of endoscopy in this group of patients.

\section{PATIENTS AND METHODS}

For a three-month period of time all patients referred because of rectal bleeding from Primary Care Units to 
our specialized Department were included prospectively. Our medical attention area comprised 133,000 inhabitants. All patients received full medical recording, physical examination, and basic blood testing (glucose, BUN, creatinine, AST, ALT, electrolytes, cell-count, hemoglobin, ESR, and coagulation status). Patients suffering from severe rectal bleeding with poor hemodynamic status, those who had previously consulted for rectal bleeding, and those who had a previous barium examination or colonoscopy were excluded from the study.

Rectal bleeding was classified into groups: benign, when in the starting of defecation; terminal, after cleansing maneuvers and when paper deposits existed, or dropping after evacuation, and mixed, when found within stools. Patients were asked to report the number of previously observed episodes, and the existence of associated factors to bleeding. Such factors included: diarrhea (3 or more depositions per day), constipation (3 or less depositions per day), drug intake and existence of previous radiation therapy. A rectal digital examination was considered normal when no disease could be found in association to visual examination.

All patients received a total colonoscopic examination after informed consent and the signing of an agreement form.

Bowel preparation was done by mean of a phosphatesoda compound (8). Colonoscopy was performed under sedation (midazolam and buscapine).

The endoscopic diagnosis was considered positive and severe in the presence of polyps larger than $0.5 \mathrm{~cm}, \mathrm{CRC}$, IBD, or angiodysplasia. In the remaining it was considered negative or non-severe.

Patients-at-risk were considered those with a direct family history of CRC (parents, brother and sisters, children), coumarin intake, severe changes in blood coagulation tests, abdominal pain, changes in bowel habits, immunosuppressed patients -AIDS- and severe associated diseases; kidney, liver or heart failure, or coagulation diseases. HBP, diabetes and dyslipidemia were not considered risk factors. Non-steroidal anti-inflammatory drugs and other medications were considered on a case-by-case basis.

This protocol was approved by the Ethics Committee of the Hospital.

\section{Statistics}

A $\chi^{2}$ test was employed for dicotomic parameters. Student's t was used for continuous parameters. Values with a $p<0.05$ were considered significant.

\section{RESULTS}

One hundred and thirty-six patients who fulfilled the described criteria were included in the study. Ten were excluded because of colonoscopy refusal (6) or a previous consultation for rectal bleeding (4).

Out of 126 included, 80 were men and 46 were women. Median age was of 49.2 years (range:19-80). Sixty-three were older than 50 years. Rectal bleeding was benign in $109(86.5 \%)$ and mixed with stools in 17 $(13.5 \%)$ patients. The anal digital examination was normal in 57 (40.5\%) and abnormal in 75 (59.5\%) (Table I). Average time of rectal bleeding history was 10 months (range: $1-120$ ), and $47.6 \%$ of cases (59 patients) presented with less than 6 episodes of bleeding. In 85 patients $(67.5 \%)$ no previous triggering factors could be described. In the remaining 41 patients $(32.5 \%)$, most common factors were: constipation in 27 , diarrhea in 7 , both mixed in 4, drug intake-associated diarrhea in 2 , and previous radiation therapy in 1 . In 36 patients $(28.5 \%)$ associated risk factors could be identified: 12 had a family history of CRC, 9 severe diseases, 8 abdominal pain or changes in bowel habits, 6 had blood test changes (anemia, elevated ESR, elevated fibrinogen, and in one case because of a constitutional syndrome). Patients taking non-steroid anti-inflammatory drugs were 22 , and 41 patients were on some form of medication (more than 4 days a week).

Colonoscopy -complete and up to the cecum- was performed in 104 patients $(82.5 \%)$, and severe disease was found in 22: 10 with large polyps, 6 with CRC, and 6 with IBD (Table II). Patients older than 50 years and those with associated risk factors showed a higher risk ( $\mathrm{p}$ $<0.05$ ). Neither the evolution time of rectal bleeding nor digital examination were associated with a higher risk of severe disease.

Table I. Rectal examination findings according to age

\begin{tabular}{lccc}
\hline Findings & $\leq \mathbf{5 0}$ years & $>\mathbf{5 0}$ years & No. patients (\%) \\
\hline None & $27(42.8 \%)$ & $24(38 \%)$ & $51(40.5 \%)$ \\
Internal hemorrhoids & $24(38 \%)$ & $20(31.7 \%)$ & $44(35 \%)$ \\
External hemorrhoids & $6(9.5 \%)$ & $10(15.8 \%)$ & $16(13 \%)$ \\
Mixed hemorrhoids & $3(4.7 \%)$ & $6(9.5 \%)$ & $9(7 \%)$ \\
Anal fissure & $2(3.1 \%)$ & $3(4.7 \%)$ & $5(4 \%)$ \\
Internal hsemorrhoids, & $1(1.5 \%)$ & & $1(0.5 \%)$ \\
*anal fistula & & & \\
\hline
\end{tabular}

Ten patients had polyps $0.5-5 \mathrm{~cm}$ in size -2 in the rectum, 7 in the sigmoid, and 1 in the right colon. CRC was found in the rectum (3) and the sigmoid (3). In 20 patients, diverticula were present (18 had more than 50 years of age). Older-age patients had a significantly higher risk for diverticular disease $(\mathrm{p}<0.05)$.

Out of 63 patients younger than 50 years, 27 had a normal digital and visual anal examination. Colonoscopy findings in this group included: 22 internal hemorrhoids, 1 mixed-hemorrhoid, 2 ulcerative colitis (one with rectal and one with rectal and sigmoid involvement), 1 small polyp in one, and a lymphoid hyperplasia of the ileum in 
Table II. Risk factors, seriousness of disease, and localization according to age

\begin{tabular}{lcc}
\hline Age & $\leq \mathbf{5 0}$ years & $>\mathbf{5 0}$ years \\
\hline Risk factors & $12(19 \%)$ & $24(63 \%)$ \\
FH of CRC & 8 & 4 \\
Laboratory changes & 3 & 3 \\
Severe diseases & 1 & 8 \\
Pain or IH changes & 0 & 8 \\
Constitutional syndrome & 0 & 1 \\
NSAIDs & $4(6 \%)$ & $18(29 \%)$ \\
Other medications & $8(12 \%)$ & $33(52 \%)$ \\
Seriousnness of disease & $5(8 \%)$ & $17(23 \%)$ \\
Ell1 & 5 & 1 \\
Tumoral polyps & 0 & 6 \\
CRC & 0 & \\
Localization of disease & & $10(29 \%)$ \\
Rectum & & \\
Sigmoid colon & $4(80 \%)$ & \\
Left colon & $1(20 \%)$ & \\
Transverse colon & & \\
Right colon & & \\
\hline
\end{tabular}

another. Among this group of 63 patients, two had diveticula and $7(11 \%)$ micropolyps ( 3 in the rectum, 3 in the sigmoid, and 1 in the transverse colon). None had polyps larger than $5 \mathrm{~mm}$ in diameter.

In the group of patients older than 50 years -63 - the digital rectal examination was normal in $24(38 \%)$ and abnormal in $39(62 \%)$ (Table I). In the group of 24 patients $(38 \%)$ with a normal digital and visual anal examination, endoscopy demonstrated internal hemorrhoids in $16(67 \%)$ and severe disease in $8(33 \%)-2$ with CRC (both in the rectum, at 9 and $0 \mathrm{~cm}$ ) and 6 polyps from 1 to $5 \mathrm{~cm}$ in size, located one in the rectum and 5 in the sigmoid colon. In the group of $39(62 \%)$ with a normal digital and visual anal examination, severe disease was found in $9(23 \%)$ instances: 4 patients had CRC (one in the rectum and three in the sigmoid), 4 patients had polyps (one in the rectum, two in the sigmoid, and one in the right colon, 0.5 to $2 \mathrm{~cm}$ in size), one patient had ulcerative colitis involving the cecum -ileal biopsies were normal. Of these 63 patients $18(29 \%)$ had diveticula and $9(14 \%)$ had micropolyps ( 2 in the rectum, 3 in the sigmoid, 1 in the transverse colon, 1 in the cecum, and 2 all over the colon). None presented with CRC or polyps measuring more than $5 \mathrm{~mm}$ in size.

\section{DISCUSSION}

The most common cause of rectal bleeding in all age groups and in published series are hemorrhoids, ranging from 27 to $72 \%(9,10)$ according to various authors. In our study group $55 \%$ of patients had demonstrable hemorrhoids. Another cause observed in patients older than 40 years were polyps, their incidence ranging from 13 to $22 \%$, and CRC, seen in 1.2 to $22 \%$ of cases $(11,12)$. In our study we found no polyps or CRC in patients younger than 51 years, but as many as $16 \%$ of patients older than 50 years had polyps, and $9.5 \%$ had CRC. The risk associated with CRC development includes age (more than 50 years) and blood mixed with stools (1-3,5-7,9-14). The majority of authors agree that the number of episodes of rectal bleeding (more than 5) and the amount of discharge $(>5 \mathrm{cc})$ cannot be considered risk factors $(2,12)$. Other risk factors that remain controversial include: decreased stool caliber (12) and recentness of bleeding (2). Most studies do not include other risk factors such as non-steroid anti-inflammatory drugs, a history of abdominal pain, or fever.

IBD was the second cause of severe disease encountered in this study in young people -younger than 51 years $(8 \%)$. Some authors report a prevalence of this disease between 6 and $16 \%$ of all patients with rectal bleeding (15).

Other causes producing rectal bleeding include ulcerative colitis, diverticular disease, and diseases of vascular origin, mainly angiodysplasia. We found no cases of ischemic colitis or angiodysplasia, probably because patients with severe bleeding were referred directly to the Hospital's Emergency Room and not to our clinic. Diverticular disease was a common finding in the older-age group of patients. However, bleeding could not be attributable to diverticular disease in any case. In the study by Acosta et al. (15), the presence of diverticula was observed in $2 \%$ of patients younger than 40 years, a figure similar to our results (3\% in those younger than 51 years).

We also observed, as is known, that in a large majority of instances $(91 \%)$ the cause of bleeding was distal to the splenic angle and mostly in the rectum and sigmoid colon $(9,14,16,17)$. In some series this figure reaches $95 \%(9)$. In this study only one patient complaining of rectal bleeding had a polyp proximal to the splenic angle in the right colon. In the remaining patients the disease was located in the rectum and sigmoid colon (15 cases).

In conclusion, it is our opinion that, in patients with rectal bleeding older than 50 years and in those associated with age-independent risk factors, endoscopy must be performed at least up to the splenic angle. In patients younger than 50 years a rectoscopy should be performed to rule out IBD.

\section{REFERENCES}

1. Fijten GH, Blijham GH, Knottnerus JA. Occurrence and clinical significance of overt blood loss per rectum in the general population and in medical practice. Br J Gen Pract 1994; 44: 320-5.

2. Helfand M, Marton KI, Zimmer-Gembeck MJ, Sox HC. History of visible rectal bleeding in a primary care population. Initial assessment and 10-year folllow-up. JAMA 1997; 277: 44-8.

3. Dent OF, Goulston KJ, Tennant CC, Langeluddecte P, Mant A, Chapuis PH, et al. Rectal bleeding: patient delay in presentation. Dis Colon Rectum 1990; 33: 851-7.

4. Kang JY, Rink E, Sundaram KK, Hartley I. Factors associated with the frequency of stool examination: effect on incidence of reported rectal bleeding. Eur J Gastroenterol Hepatol 2003; 15: 531-3. 
5. Talley NJ, Jones M. Self-reported rectal bleeding in a United States community: prevalence, risk factors, and health care seeking. Am J Gastroenterol 1998; 93: 2179-83.

6. Sladden MJ, Thomson AN, Lombard CJ. Rectal bleeding in general practice patients. Aust Fam Physician 1999; 28: 750-4.

7. Alonso P, Marzo M, Mascort JJ, Hervas A, Vinas L, Ferrus J, et al. Clinical practice guidelines for the management of patients with rectal bleeding. Gastroenterol Hepatol 2002; 25: 605-32.

8. Bujanda L, Muñoz C, Sánchez A, Iriondo C, Ramos F, SánchezLlona B, et al. Tolerance to and colon cleasing with 2 preparations. Polyethylene glycol or sodium phosphate. Gastroenterol Hepatol 2001; 24: 9-12.

9. Shinya H, Cwern M, Wolf G. Colonoscopic diagnosis and management of rectal bleeding. Surg Clin North Am 1982; 62: 897-903.

10. Goulston KJ, Cook Y, Dent OF. How important is rectal bleeding in the diagnosis of bowel cancer and polyps? Lancet 1986; 261-5.

11. Pines A, Shemesh E, Bat L. Prolonged rectal bleeding associated with hemorrhoids: The diagnostic contribution of colonoscopy. South Med J 1987; 80: 313-4.
12. Van Rosendaal GMA, Sutherland LR, Verhoef MJ, Bailey RJ, Blustein PK, Lalor EA, et al. Defining the role of fiberoptic sigmoidoscopy in the investigation of patients presenting with bright red rectal bleeding. Am J Gastroenterol 2000; 95: 1185-7.

13. Mant A, Bokey EL, Chapues PH, Killingback M, Hughes W, Koorey SG, et al. Rectal bleeding. Do other symptoms aid in diagnosis? Dis Colon Rectum 1989; 32: 191-6.

14. Toomey P, Aimakopoulos G, Zbar A, Kmiot W. "One-stop" rectal bleeding clinics without routine flexible sigmoidoscopy are unsafe. Ann R Coll Surg Engl 1998; 80: 131-3.

15. Acosta JA, Fournier TK, Knutson CO, Ragland JJ. Colonoscopic evaluation of rectal bleeding in young adults. Ann Surg 1994; 60: 903-6.

16. Church JM. Analysis of the colonoscopic findings in patients with rectal bleeding according to the pattern of their presenting symptoms. Dis Colon Rectum 1991; 34: 391-5.

17. Segal WN, Greenberg PD, Rockey DC, Cello JP, McQuaid KR. The outpatient evaluation of hematochezia. Am J Gastroenterol 1998; 93 : $179-82$ 